\title{
Konfrontasi Iran-Amerika Serikat di Selat Hormuz dan Dampaknya bagi Distribusi Penjualan Minyak Dunia
}

\author{
Wandy Ardiyansyah Hasibuan \\ Program Studi IImu Hubungan Internasional Fakultas IImu Sosial dan IImu Politik \\ Universitas Riau \\ e-mail : wandyardiyansyah98625@gmail.com
}

\begin{abstract}
This paper will discuss why the confrontation between Iran and the United States (US) in the Strait of Hormuz occurred. After withdrawing from the Joint Comprehensive Plan of Action (JCPOA) agreement, US unilaterally giving back their sanctions to Iran and made relations between the two countries heated up again. Iran then responded with snarling to close the Strait of Hormuz. This response makes other countries in the world who have an interest in buying oil from the Middle East under threat. The US felt aggrieved by this threat; the country performs maneuvers and military confrontation in the Strait of Hormuz. This action caused oil traffic through the strait disturbed, and global oil distribution also harmed. By using qualitative methods and implementing Lovell's theory of Foreign Policy Strategy, the author finds that Iran and US use the Confrontation Strategy approach in its foreign policy, which prioritized contradictory national interests. As a result, it is predicted that the confrontation in the Strait of Hormuz will continue as long as the two sides hold their current positions.
\end{abstract}

Keywords: Strait of Hormuz, crude oil supply, foreign policy strategy, JCPOA, USIran confrontation

\begin{abstract}
Abstrak
Tulisan ini akan membahas tentang mengapa konfrontasi Iran dan Amerika Serikat (AS) di Selat Hormuz bisa terjadi. Setelah menarik diri dari perjanjian Joint Comprehensive Plan of Action (JCPOA), AS secara sepihak mengembalikan sanksi kepada Iran dan membuat hubungan kedua negara kembali memanas. Iran kemudian merespons dengan menggertak akan menutup Selat Hormuz. Hal ini membuat negara-negara yang memiliki kepentingan untuk membeli minyak dari Timur Tengah merasa terancam. AS sebagai pihak yang merasa sangat dirugikan
\end{abstract}


dengan ancaman tersebut melakukan sejumlah manuver dengan melakukan konfrontasi militer di Selat Hormuz. Tindakan ini menyebabkan lalu lintas minyak yang melalui selat tersebut menjadi terganggu, dan distribusi minyak dunia pun turut terpengaruh. Dengan menggunakan metode kualitatif dan mengimplementasikan teori Strategi Kebijakan Luar Negeri dari Lovell, penulis menemukan bahwa Iran dan AS menggunakan pendekatan Confrontation Strategy dalam kebijakan luar negerinya, yang mengutamakan usaha mencapai kepentingan nasional yang saling berlawanan. Sebagai akibatnya, diprediksi bahwa konfrontasi di Selat Hormuz akan terus terjadi selama kedua pihak masih bertahan dalam posisinya masing-masing.

Kata kunci: JCPOA, konfrontasi AS-Iran, pasokan minyak mentah, Selat Hormuz strategi kebijakan luar negeri

\section{Pendahuluan}

Sumber energi merupakan kebutuhan yang penting bagi suatu negara, khususnya minyak dan gas yang menjadi sumber energi pembangkit di bidang industri. Minyak dan gas kebanyakan berasal dari kawasan Timur Tengah, banyak negara di kawasan tersebut yang menjadi negara pengekspor minyak. Minyak-minyak tersebut kemudian didistribusikan melalui jalur lalu lintas laut, yaitu Selat Hormuz. Selat Hormuz adalah salah satu titik vital distribusi minyak dunia karena besarnya volume minyak yang melalui selat tersebut. Menurut data yang dilansir dari US Energy Information Administration (EIA) pada tahun 2018, rata-rata jumlah minyak yang melewati selat itu dapat mencapai jumlah 28 juta barel minyak per hari, yang mana artinya setara dengan $21 \%$ konsumsi minyak bumi global (U.S. Energy Information Administration, 2019).

Selat Hormuz adalah satu-satunya jalur air yang mengarah keluar dari Teluk Persia. Semua kapal tanker yang mengirim atau mengambil minyak dari pelabuhan Teluk Persia harus melewati selat ini. Selat ini dikuasai oleh tiga negara, Iran menguasai pantai utara selat, sedangkan Oman dan Uni Emirat Arab menguasai pantai selatan. Panjang total selat tersebut mencapai 180 kilometer dan pada titik tersempitnya, lebar selat hanya 45 kilometer. Selat ini dilalui dua jalur pelayaran, masing-masing jalur memiliki lebar 3,2 kilometer, dengan zona penyangga 3,2 kilometer di antaranya (Talmadge, 2008). Posisi geografis Selat Hormuz juga sangat strategis, yaitu berada di antara Iran dan Oman, dan dihubungkan oleh Teluk Persia dan Teluk Oman (Katzman et al., 2012: 2). Lokasi ini menjadi jalur tercepat bagi lalu lintas minyak global yang akan diekspor ke berbagai kawasan, khususnya ke kawasan 
Asia yang merupakan salah satu kawasan importir terbesar minyak mentah dunia, sehingga menjadikan selat ini jalur lalu lintas maritim yang tersibuk dunia.

Posisi Selat Hormuz yang strategis menjadikan wilayah perairan ini rawan konflik. Iran mengklaim Selat Hormuz adalah wilayah kedaulatannya dan mengancam akan melakukan penutupan jika AS atau Israel menyerang Iran atau melakukan sanksi. Iran dan AS berkali-kali terlibat dalam perseteruan verbal mengenai selat ini. Misalnya, pada bulan Juli 2018, pemerintahan Trump meminta semua negara untuk menghentikan impor minyak dari Iran. Hal ini direspon oleh Presiden Rouhani bahwa bila ancaman AS itu dilaksanakan, Iran memiliki kemampuan untuk menutup jalur distribusi minyak dunia. Pernyataan ini diperjelas oleh Komandan Garda Revolusi Iran, Mohammad Ali Jafari, "Kami akan membuat musuh kami memahami bahwa Straits Hormuz bebas dilewati semua pihak, atau tidak sama sekali." Pernyataan ini kemudian dibalas oleh Bill Urban, juru bicara US Central Command, bahwa AS dan sekutunya akan menjaga keamanan di kawasan dan tidak akan tinggal diam di hadapan ancaman Iran (Dehghan, 2018).

Seandainya Iran melaksanakan ancamannya dan menghalangi Selat Hormuz dilewati oleh negara lain jal ini merupakan pelanggaran atas Konvensi Perserikatan Bangsa-Bangsa tentang Hukum Laut (UNCLOS), di mana Iran juga telah menandatanganinya. Konflik di Selat Hormuz telah terjadi sejak tahun 1980-an, yaitu ketika terjadi perang tanker antara Iran dan Irak. Namun, belakangan pada tahun 2018-2020, konflik yang terjadi adalah konfrontasi militer antara Iran dan Amerika Serikat (AS). Sebagaimana telah disinggung sebelumnya, pada Juli 2018 Presiden AS Donald Trump meminta negara-negara dunia tidak lagi membeli minyak dari Iran. Hal ini merupakan kelanjutan dari langkah Trump bulan Mei 2018 yang menarik negaranya keluar dari kesepakatan Joint Comprehensive Plan of Action (JCPOA).

JCPOA adalah sebuah kesepakatan tentang nuklir Iran di mana melalui kesepakatan tersebut, 5 negara besar dunia (AS, Inggris, Prancis, Rusia, China, dan Uni Eropa yang diwakili Jerman) bersepakat mencabut sanksi dan embargo atas Iran, dan sebaliknya Iran bersedia untuk mengurangi dan menghentikan aktivitas program nuklirnya (Mikail, 2018: 77). Sebelumnya, Iran dituduh Israel dan AS telah mengembangkan teknologi senjata nuklir, dan oleh karenanya Iran mendapatkan sanksi embargo yang membuat ekonomi mereka tertekan (Mikail, 2018: 75). Aksi sepihak yang dilakukan Presiden Trump ini menjadi sorotan dunia internasional, sebab JCPOA dianggap sebagai sebuah kesepakatan yang dapat membuat hubungan Iran dengan Barat menjadi lebih baik. Keluarnya AS dari kesepakatan ini, ditambah dengan kembalinya beberapa sanksi terhadap Iran, membuat Iran merespon dengan mengancam akan menutup Selat Hormuz (Dehghan, 2018). 
Konfrontasi Iran-AS menciptakan ketegangan di kawasan tersebut dan menarik perhatian masyarakat internasional, sebab Selat Hormuz merupakan jalur distribusi bagi seperlima pasokan minyak global dunia (Pujayanti, 2019: 10). Untuk menjelaskan bagaimana proses konfrontasi tersebut terjadi, penulis akan menggunakan teori Strategi Kebijakan Luar Negeri dari John P. Lovell yang akan dijelaskan lebih jauh di bagian kerangka konseptual.

Ada sejumlah karya riset terdahulu yang dijadikan sumber rujukan oleh penulis, yang berkaitan dengan tema yang diangkat dalam tulisan ini, di antaranya Saputra (2013) meneliti latar belakang wacana penutupan Selat Hormuz oleh Iran dan menemukan bahwa tekanan politik dari negara-negara Barat, khususnya AS, merupakan penyebab munculnya upaya Iran untuk menaikkan daya tawarnya di selat tersebut. Nuriansyah (2014) meneliti konflik AS-Iran di Selat Hormuz dengan menganalisis aspek kebijakan pertahanan Iran dengan menggunakan teori Strategi dan Kebijakan Pertahanan. Faradiba (2016) meneliti sikap AS terhadap kegiatan militer Iran di Selat Hormuz di masa kepresidenan Ahmadinejad (2011-2013). Rahim (2019) menjelaskan tentang kebijakan AS terhadap Iran yang semakin koersif pasca perjanjian JCPOA. Sementara itu, dalam penelitian ini, penulis akan menganalisis konflik kedua negara di Selat Hormuz dalam perspektif strategi kebijakan luar negeri, dengan menggunakan pandangan dari John P. Lovell (1970).

\section{Strategi Kebijakan Luar Negeri}

Dalam menganalisis kasus ini, penulis menggunakan teori Strategi Kebijakan Luar Negeri dari John P. Lovell yang akan menjelaskan bagaimana strategi kebijakan luar negeri Iran dan AS di Selat Hormuz telah mengakibatkan ketidakamanan di wilayah dan berpotensi menimbulkan konfrontasi militer yang berkelanjutan. Lovell 1970 (dalam Yani, 2008:1-2) berpendapat bahwa ada sejumlah faktor penting yang mempengaruhi proses strategi kebijakan luar negeri suatu negara-bangsa, yaitu: (1) struktur sistem internasional, (2) persepsi elit, (3) strategi negara-bangsa lain, dan (4) kapabilitas yang dimiliki oleh negara tersebut.

Selanjutnya, keempat faktor ini menentukan bagaimana negara-negara saling berinteraksi dan menentukan strategi mereka dalam menghadapi satu sama lain. Lovell (dalam Yani, 2008:2-3) membuat tipologi empat jenis strategi kebijakan luar negeri, yaitu leadership strategy, confrontatition strategy, accommodative strategy, dan concordance strategy. Leadership strategi dilakukan ketika sebuah negara (misalnya negara A) lebih memilih cara persuasi dan tawar-menawar daripada melalui cara kekerasan terhadap negara B. Hal ini dilakukan karena negara A memandang 
dirinya memiliki kapabilitasnya superior dan superioritas itu diakui oleh B sehingga $B$ mau mematuhi $A$.

Sementara itu, concordance strategy mengacu pada kondisi dimana kedua negara berada dalam posisi yang saling membutuhkan dan menguntungkan. Dalam kondisi ini, negara $B$ yang mengakui bahwa kapabilitasnya relatif lebih rendah daripada negara $A$, akan berusaha untuk menjalin hubungan baik dengan negara $A$ dan berperilaku yang sejalan dengan kebijakan negara A. Tipe ke-3 dan 4, yaitu confrontation strategy dan accomodation strategy terjadi secara simultan. Negara A yang superior cenderung memperuncing isu-isu yang melanggar kepentingan negara $B$ sehingga memaksa negara B untuk memodifikasi posisinya (accomodation) melalui pengakuan terhadap superioritas kapabilitas negara A demi menghindari konflik. Namun dalam jangka panjang, B kemungkinan akan melakukan perlawanan (confrontation) terhadap A bila kapasitasnya meningkat (Lovell, 1970:100).

Keempat tipe strategi di atas digambarkan dalam diagram berikut ini.

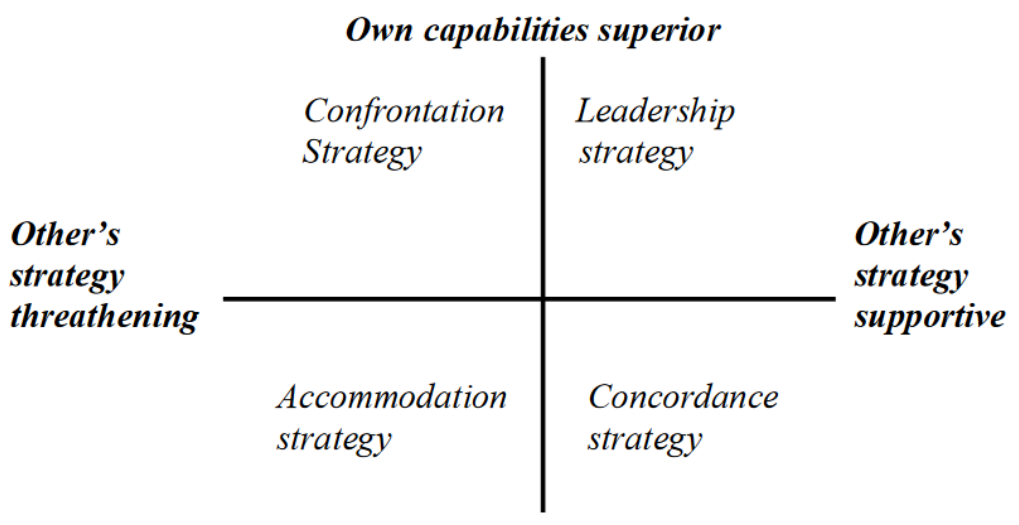

Own capabilities inferior

(sumber diagram: Yani, 2008:3)

Menurut Kamus Besar Bahasa Indonesia, makna konfrontasi berarti perihal berhadap-hadapan langsung, permusuhan, pertentangan, atau cara menentang musuh atau kesulitan dengan berhadapan langsung dan terang-terangan. Sedangkan makna dari kata strategi menurut Lovell adalah serangkaian langkah-langkah atau keputusankeputusan yang dirancang sebelumnya dalam situasi kompetitif di mana hasil akhirnya tidak semata-mata bersifat untung-untungan (Mas'oed, 1998).

Dasar pemikiran di atas mengakui bahwa negara merupakan aktor yang rasional dan dianggap selalu mengejar tujuan nasional berdasarkan kalkulasi tertentu dalam panggung politik internasional. Fokus dalam tulisan ini terdapat pada 
penekanan aksi-reaksi antar aktor-aktor yang saling terlibat dan tidak hanya terfokus pada pihak yang memberikan tanggapan saja. Di dalam perspektif strategi, pola umum dari kesinambungan dan perubahan politik luar negeri dijelaskan berdasarkan tujuantujuan strategis para pembuat keputusan.

Meskipun Lovell membagi mekanisme kebijakan luar negeri melalui empat tipe, namun penulis akan mengembangkan pembahasan tulisan ini hanya dengan menggunakan pendekatan Confrontation Strategy. Hal itu dikarenakan penulis menilai bahwa pendekatan Confrontation Strategy sudah dapat menjelaskan pola-pola kebijakan yang diambil oleh Iran dan AS yang membuat konflik ini dapat terjadi.

\section{Iran dan JCPOA}

Situasi konflik bersenjata yang berada di kawasan Timur Tengah bukanlah hal yang baru. Iran sebagai salah satu negara produsen minyak terbesar memiliki sejarah konflik yang panjang, baik itu dengan negara-negara di sekitarnya, seperti Irak, maupun dengan negara super power seperti AS. Awal mula konflik Iran dengan AS dimulai sejak tergulingnya rezim monarki Mohammad Reza Pahlevi yang didukung oleh AS pada tahun 1979. Tahun-tahun berikutnya, AS memberlakukan berbagai embargo berupa sanksi keuangan atau perbankan dan sanksi ekspor minyak, atau pelarangan terhadap Iran untuk mengekspor minyak (Salsabila \& Yulianti, 2019).

Sejak tahun 2006, sanksi yang diberikan kepada Iran selalu dikaitkan dengan program nuklir. Pasalnya, Iran tidak mau menghentikan program pengayaan uraniumnya. Meskipun Iran menandatangani NPT (Perjanjian Nonproliferasi Nuklir), AS bersama dengan Israel selalu menuduh bahwa Iran sedang mengembangkan senjata nuklir yang dapat mengancam keamanan dunia. Misalnya, pada 2019, PM Israel, Netanyahu di pertemuan IAEA Di Berlin mengklaim telah menemukan situs nuklir baru Iran di daerah Abadeh dan meminta IAEA bertindak lebih keras kepada Iran (VOA Indonesia, 2019).

Sejak Iran mengungkapkan program nuklirnya pada tahun 2002, AS berulang kali menuduh Iran melanggar perjanjian pengamanan Non-Proliferation Treaty (NPT). Selain itu, ditemukan pula anak perusahaan Iran yang melakukan beberapa aktivitas nuklir dengan tidak memberitahukannya terlebih dahulu kepada International Atomic Energy Agency (IAEA). Hal lainnya, Iran juga disebut telah membangun fasilitas nuklir tanpa sepengetahun dari IAEA (Carrel-Billiar \& Wing, 2010). Selain masalah nuklir, hubungan Iran dan AS menjadi buruk dan berkepanjangan karena adanya alasan historis, yaitu Revolusi Iran 1979. Akibat revolusi ini, hubungan kedua negara yang tadinya bersahabat, menjadi bertolak belakang dan saling bermusuhan. Selain itu, Iran juga dituduh telah membentuk pasukan proxy di wilayah Timur Tengah yang menyebabkan ketidakstabilan kawasan (Council on Foreign Relations, 2020). 
Bagaimanapun kegiatan pengembangan nuklir menjadi isu yang sangat penting bagi keamanan dunia internasional. Karena jika kita belajar dari sejarah, yakni saat Perang Dunia II, ketika kekuatan bom nuklir dapat menghancurkan dua kota di Jepang, yaitu Hiroshima dan Nagasaki, nuklir dapat menjadi senjata pemusnah massal yang membahayakan kehidupan manusia. Hal inilah akhirnya yang mendorong AS memprakarsai dibentuknya IAEA, yang secara resmi berdiri pada tanggal 29 Juli 1957 dengan jumlah negara yang menyetujui statuta ini sebanyak 81 negara. Kemudian dalam usaha untuk menciptakan perdamaian dunia yang bebas dari senjata nuklir, masyarakat internasional menyepakati perjanjian NPT pada tanggal 12 Juni 1968 dengan tujuan untuk mencegah tersebarnya senjata nuklir dan meningkatkan penggunaan nuklir untuk tujuan damai, sekaligus mempercepat langkah-langkah pelucutan senjata nuklir di dunia (Mikail, 2018: 73).

Setelah beberapa periode kepemimpinan, pada masa Presiden Mahmud Ahmadinejad, Iran mengalami hubungan yang semakin memburuk dengan Barat, khususnya AS. Berulang kali AS meminta IAEA untuk mengadakan inspeksi nuklir ke Iran karena mereka curiga bahwa Iran sedang mengembangkan senjata nuklir. Lebih jauh, AS bahkan melakukan kebijakan embargo ekonomi terhadap Iran. Pada masa pemerintahan Obama, AS pada akhirnya menggunakan pendekatan diplomasi yang lebih konstruktif terhadap Iran dengan menginisiasi Perjanjian JCPOA itu akan membatasi pengembangan nuklir Iran dengan imbalan pencabutan sanksi ekonomi didukung oleh Presiden Obama, meskipun Kongres AS menentang kesepakatan ini (Perwita \& Razak, 2020:22). Perjanjian ini ditandatangani oleh Iran dan AS, serta seluruh negara anggota tetap Dewan Keamanan PBB lainnya dan Uni Eropa yang diwakili oleh Jerman (biasa diistilahkan "negara P5+1") pada 14 Juli 2015 di Wina, Austria.

\section{AS Menarik Diri dari Kesepakatan JCPOA}

Ketegangan antara Iran dan AS kembali meningkat semenjak kepemimpinan Presiden Donald Trump. Pada tanggal 8 Mei 2018 AS secara sepihak menarik diri dari kesepakatan JCPOA. Trump beralasan bahwa Iran telah melanggar perjanjian dan melakukan pengembangan nuklir bukan untuk tujuan damai. AS juga menuduh bahwa rezim Iran mendukung aktivitas terorisme, mengekspor kekerasan, dan mendatangkan kehancuran di Timur Tengah (Aljazeera, 2019). Langkah konfrontatif yang dilakukan AS membuat kesepakatan yang telah ditandatangani oleh Iran dan P5+1 tersebut menjadi terganggu dan menyebabkan konflik antar Iran dan AS terbuka kembali. Langkah yang diambil AS ini membuat perhatian dunia internasional tertuju ke Timur Tengah, sebab wilayah ini merupakan wilayah penghasil minyak mentah yang sangat banyak dengan konsumen dari berbagai belahan dunia. 
Eskalasi hubungan Iran dan AS kemudian semakin memburuk ketika presiden Iran, Hasan Rouhani, pasca keluarnya AS dari JCPOA, mengatakan, "Iran siap untuk melanjutkan kegiatan nuklirnya dengan intensitas lebih dari sebelum perjanjian nuklir jika kesepakatan itu dibatalkan, semua opsi terbuka" (Bacon, 2018). Hal ini juga selaras dengan perintahnya untuk menambah jumlah pengayaan uranium jika AS memberikan sanksi terhadap Iran. Berdasarkan aturan IAEA, level pengayaan uranium yang legal adalah 3-5\% dan Iran diberi keleluasaan memperkaya uranium hingga maksimal 3,6\%. Sementara, level pengayaan uranium yang dibutuhkan dalam rangka produksi senjaat nuklir adalah 90\%. Jelas bahwa setelah AS mundur dari JCPOA hubungan kedua negara menjadi tegang, selain itu masyarakat internasional yang memiliki kepentingan di Timur Tengah juga turut merasa terganggu.

\section{Selat Hormuz dan Urgensinya sebagai Jalur Lalu Lintas Minyak Mentah Dunia}

Selat Hormuz adalah jalur air yang sempit yang menghubungkan antara Teluk Persia dan Teluk Oman yang akhirnya akan menuju Laut Arab. Selat ini merupakan jalur transit minyak mentah yang terpenting di dunia sebab jumlah minyak yang melintasi selat ini cukup banyak. Seiring dengan semakin berkembangnya proses perindustrian negara-negara di dunia, permintaan akan minyak terus meningkat dan sekaligus meningkatkan harga minyak di dunia.

Hal ini tentunya berkaitan dengan Timur Tengah yang merupakan salah satu kawasan penyumbang minyak mentah terbesar di dunia, pasalnya kebanyakan dari anggota organisasi The Organization of the Petroleum Exporting Countries (OPEC) seperti Arab Saudi, Irak, Uni Emirat Arab (UEA), Kuwait, dan Iran berasal dari sana. Fakta ini menjadikan kawasan tersebut strategis bagi perdagangan minyak dunia. Namun, mengingat kondisi konflik di Selat Hormuz, kapal-kapal minyak yang seharusnya dapat melewati jalur ini dengan aman harus mencari jalur alternatif lain agar terhindar dari berbagai ancaman di sekitaran selat.

Diagram berikut ini menunjukkan data minyak mentah dan kondensat yang melewati Selat Hormuz serta peta jalur alternatif, yaitu Abqaiq-Yanbu dan Abu Dhabi. 


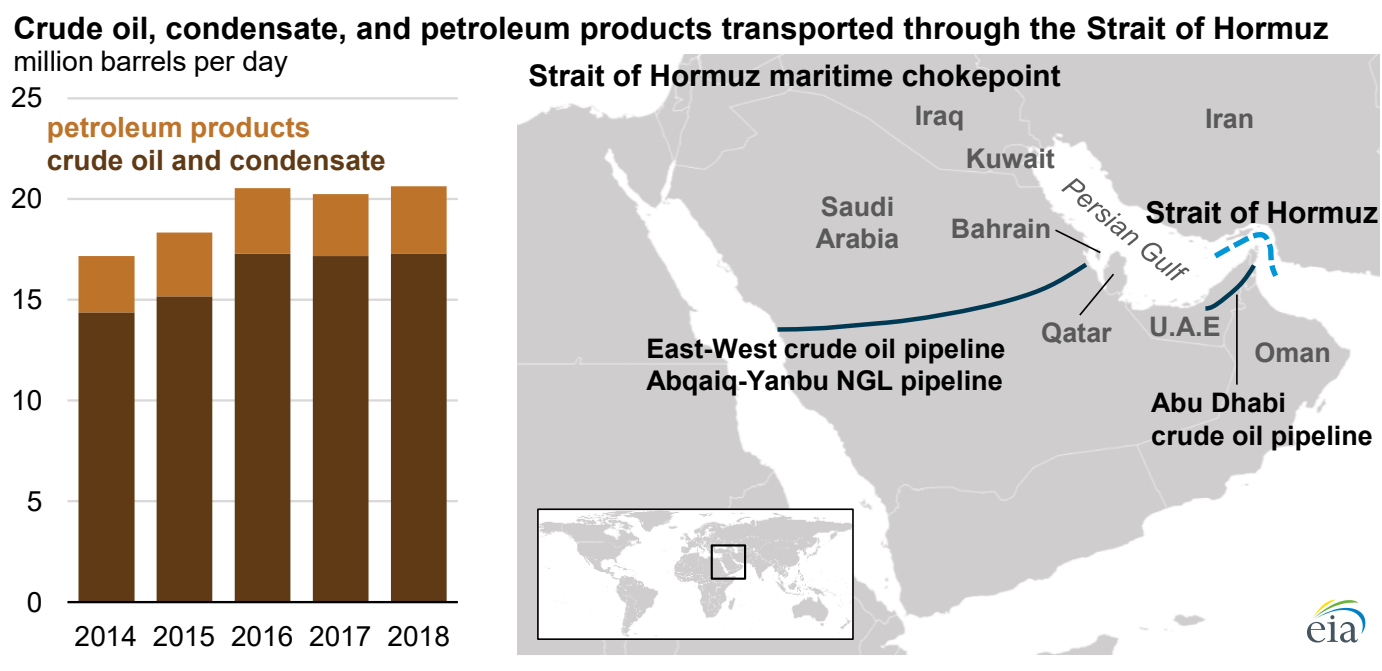

Sumber: U.S. Energy Information Administration and ClipperData, Inc.

Di sisi lain, terdapat jalur alternatif lain untuk memotong jalur Selat Hormuz, yaitu melalui pipa minyak. Jalur ini dimanfaatkan oleh Arab Saudi dan UEA jika di Selat Hormuz sedang terjadi kondisi yang membahayakan. Terdapat dua jalur pipa minyak alternatif, yaitu Abqaiq-Yanbu dan Abu Dhabi. Pipa minyak Abqaiq-Yanbu bermula dari Teluk Persia menuju Semenanjung Arab dan berakhir di Laut Merah. Kemudian pipa minyak Abu Dhabi dimulai dari Abu Dhabi, memutari Selat Hormuz, melewati Uni Emirat Arab, dan menuju ke Teluk Oman (Ratner, 2018: 5-6)

Meskipun jalur alternatif tersebut lebih aman, namun mereka memiliki kekurangan, yaitu waktu distribusi yang lebih lama, biaya yang lebih besar, dan kurangya akses dan kapasitas yang memadai untuk membawa semua produksi minyak dan gas menuju kawasan pasar. Meskipun Arab Saudi mampu mengirimkan sebagian minyaknya melalui jalur darat sepanjang 745 mil melalui pipa timur ke barat, yaitu dari Abqaiq yang berada dekat Teluk Persia ke Yanbu yang berada di Laut Merah, ataupun memindahkan gas alam cair (LNG) di sepanjang jalur yang sama, masalahnya adalah jalur tersebut sudah digunakan untuk produksi lain, sehingga kelebihan kapasitas yang harus melewati jalur tersebut terbatas dan tentu dapat memperlambat proses distribusi produsen menuju pasar (Pham, 2010: 65).

Kebanyakan minyak Timur Tengah diekspor menuju pasar Asia, dengan Jepang, India, Korea Selatan, dan China sebagai tujuan utamanya (ACIL Tasman, 2012: 11). China dan India merupakan negara yang paling cepat pertumbuhan ekonominya dibandingkan dengan dekade-dekade sebelumnya dan mereka diprediksi akan membutuhkan minyak yang lebih banyak untuk meningkatkan pertumbuhan ekonomi di masa depan (US Energy Information Administration, 2007). 


\section{Konsumsi Energi Negara non-OECD Berdasarkan Wilayah dalam Satuan Kuadriliun British Thermal Units}

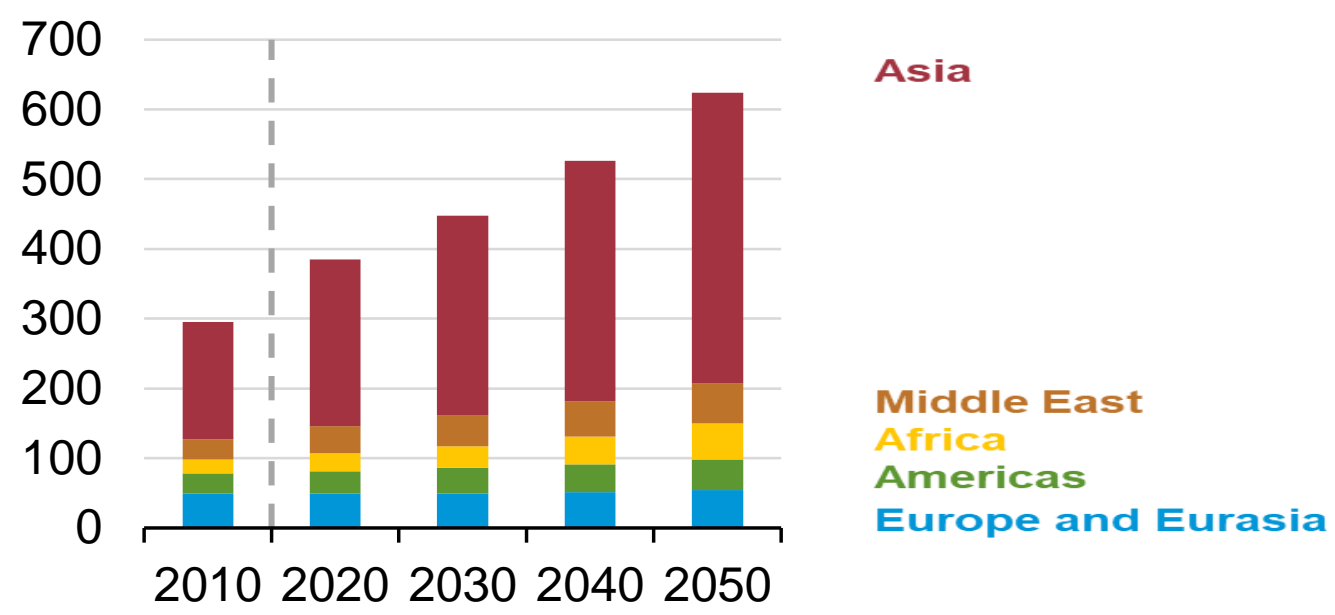

Sumber: International Energy Outlook 2019

Dari data yang dikeluarkan oleh U.S. Energy Information Administration jelas diketahui bahwa jumlah konsumsi minyak di kawasan Asia diprediksi akan terus meningkat drastis hingga tahun 2050. Hal ini terjadi karena Asia merupakan kawasan yang sedang berkembang, apalagi China dan India merupakan negara yang perkembanganya sangat cepat dan diprediksi akan menjadi pesaing baru ekonomi di masa depan (Kahn, 2016). Oleh karena itu, ancaman Iran yang mengatakan akan menutup Selat Hormuz merupakan potensi kendala yang cukup besar, karena kawasan Timur Tengah merupakan kawasan penghasil dan pengekspor minyak mentah yang penting untuk negara-negara yang bermitra dengannya, khususnya Asia. Ancaman Iran ini juga menimbulkan reaksi dari berbagai negara dan pada umumnya mereka sependapat, yaitu meminta Iran agar mampu menahan diri terhadap kebijakan politik luar negeri AS dan berusaha untuk mencari jalan keluar lain (dw.com, 2020). Tentunya menarik untuk diketahui mengapa Iran menggunakan ancamannya untuk menutup Selat Hormuz untuk yang kesekian kalinya dalam merespon tekanan AS.

\section{Konfrontasi Iran-AS}

Untuk memahami bagaimana konfrontasi antara Iran dan AS bisa terjadi, penulis menggunakan teori Strategi Kebijakan Luar Negeri oleh Lovell. Strategi dapat dimaknai sebagai serangkaian langkah-langkah atau keputusan-keputusan yang dirancang sebelumnya dalam situasi kompetitif di mana hasil akhirnya tidak sematamata bersifat untung-untungan. Strategi adalah cara yang digunakan untuk mencapai suatu tujuan atau kepentingan dengan menggunakan power yang tersedia, termasuk 
juga kekuatan militer. Dalam pelaksanaan strategi, negara akan memperhitungkan kapasitas power mereka untuk mendapatkan atau menjaga kepentingan nasionalnya. $\mathrm{Hal}$ ini sejalan dengan pemikiran kaum realis yang mengatakan kepentingan nasional adalah yang terpenting. Kepentingan nasional merupakan tujuan yang harus dicapai bagi setiap negara untuk mempertahankan keberlangsungan negaranya. Oleh karenanya negara harus menunjukkan power yang dimilikinya terhadap negara lain untuk menekan agar negara lain mau bertindak sesuai dengan kepentingannya.

Dalam kasus Selat Hormuz, AS memiliki kepentingan untuk menjaga selat itu sebagai jalur pelayaran internasional sebab mereka mengimpor minyak yang berasal dari Timur Tengah. Di saat yang sama, AS memiliki sejarah konflik yang panjang dengan Iran, yaitu sejak tumbangnya rezim monarki dukungan Iran, Pahlevi. Sebaliknya, Iran memiliki kepentingan untuk menjual minyaknya ke berbagai negara dunia, namun dihalangi oleh embargo AS. Iran memanfaatkan kedaulatan yang dimilikinya di Selat Hormuz sebagai daya tawar untuk melawan AS. Konflik antara kedua negara ini diakibatkan oleh kepentingan nasional yang berlawanan serta dipicu oleh berbagai kebijakan-kebijakan yang merugikan bagi kedua belah pihak.

Dalam kapabilitas militer yang dilansir dari Global Fire Power, posisi Iran berada jauh di bawah AS, yaitu pada peringkat ke-14 dibandingkan AS yang menempati peringkat ke-1. Dilihat dari kekuatan militer Angkatan Laut, Iran juga sangat jauh di bawah AS. Hingga kini Angkatan Laut Iran hanya memiliki 398 aset, dengan aset terbanyaknya adalah kapal selam yang berjumlah 34 unit (Global Fire Power, 2020a; 2020b). Kapal selam menjadi salah satu senjata andalan Iran untuk meletakkan ranjauranjau di bawah laut untuk mengganggu kapal-kapal yang melintas di Selat Hormuz. Meskipun mengoperasikan ranjau di sana cukup sulit karena kondisi geografisnya yang sempit, namun nyatanya Iran mampu unuk meletakkan ranjau di perairan tersebut.

Menurut Talmadge (2008: 89), Iran dapat meletakkan ranjau dari salah satu dari 3 fregat, 2 korvet, dan 10 kapal misil cepatnya. Iran juga memiliki 3 kapal di Teluk Persia yang memiliki kemampuan khusus peletakan ranjau, ditambah 3 peletakan ranjau RH-53D Sea Stallion yang masih berfungsi. Selain itu, Iran memiliki lebih dari 200 unit patrol kecil dan kombatan pantai yang cocok untuk peletakan ranjau. Selain itu Iran memiliki 3 kapal selam diesel-listrik tipe 877 Kilo yang relatif modern dari Rusia dan setidaknya 1 kapal selam menengah yang mampu memasang ranjau. Namun secara umum, catatan operasional Iran dengan kapal selam sangat kecil dan gerakannya pun lambat.

Berdasarkan data yang ditulis Talmadge tahun 2008, angkatan laut reguler Iran mencakup 18.000 pasukan aktif, serta 20.000 lainnya di Angkatan Laut Garda Revolusi 
Islam. Angkatan Laut memiliki pangkalan di sepanjang pantai, termasuk juga pangkalan udara yang besar dan markas operasional di Bandar Abbas tepat di utara selat. Iran juga memiliki hampir selusin pelabuhan domestik yang menghadap selat, dan IRGCN memiliki pos militer di pulau-pulau dekat selat: Abu Musa, Larak, dan Sirri. Iran menggunakan pulau-pulau ini sebagai pangkalan terdepan untuk kapal patroli pantai. Iran diyakini memiliki minimalnya cadangan 2000 ranjau, dan ini adalah angka yang sangat kecil dibandingkan AS dan Uni Soviet yang masing-masing menyimpan cadangan ratusan ribu ranjau selama Perang Dingin (Talmadge, 2008: 86, 90).

Talmadge menyimpulkan bahwa meskipun kekuatan Iran jauh di bawah AS, namun jika Iran bisa memanfaatkan berbagai kemampuan yang ada dengan benar, negara ini dapat menghentikan atau menghalangi lalu lintas di Selat Hormuz selama sebulan atau lebih. Jika AS meresponsnya dengan serangan militer, Talmadge memprediksikan akan terjadi operasi udara dan laut berskala besar yang berkelanjutan yang akan membebani biaya besar bagi Amerika Serikat. Karena itu, Talmadge menyarankan agar AS melakukan perubahan dalam postur kekuatan dan kebijakan energinya (Talmadge, 2008: 116).

Berdasarkan uraian di atas, penulis akan mengimplementasikan analisis dengan penggunaan perspektif Confrontation Strategy. Sebagaimana telah disampaikan di awal, ilustrasi dari tipologi konfrontasi ini adalah: jika negara $A$ hendak mempertajam isu-isu yang mengandung konflik kepentingan dengan negara $B$, maka negara $A$ akan memaksa negara B untuk memodifikasi posisinya melalui pengakuan terhadap superioritas kapabilitas negara A. Secara detail pendekatan ini memiliki proposisi kunci:

Hipotesis 1 (H1): Negara A mempertajam isu konflik terhadap negara B.

Hipotesis 2 (H2): Negara A memaksa negara B mengakui superioritas kapabilitas negara $A$.

Penulis menempatkan kebijakan-kebijakan yang dilakukan oleh masing-masing pihak dalam merespon konflik di Selat Hormuz. Penulis akan menjelaskan model ini dimulai dari sejak keluarnya AS dari kesepakatan JCPOA pada tanggal 8 Mei 2018.

\section{Skenario 1}

AS menarik diri dari kesepakatan JCPOA dengan alasan Iran telah mengembangkan aktivitas nuklir untuk kepentingan militer dan menetapkan beberapa sanksi terhadap Iran, di antaranya pembatasan pembelian mata uang AS oleh Iran, pembatasan penjualan onderdil mekanik seperti mobil, pesawat, dan lain-lain. Namun sanksi yang paling memberatkan adalah diberlakukannya kembali embargo ekonomi 
yang sebelumnya telah dihapus pada saat kesepakatan JCPOA masih berlaku (Council on Foreign Relations, 2018). Selain itu, AS juga meminta Iran untuk segera menghentikan aktivitas nuklirnya.

Dari skenario 1 ini dapat diketahui bahwa AS telah menggunakan pendekatan Confrontation Strategy terhadap Iran. Hal ini sesuai dengan proposisi kunci itu sendiri, sebagaimana telah disebutkan di atas:

H1: Negara A mempertajam isu konflik terhadap negara B:

AS keluar dari kesepakatan JCPOA dan menerapkan sanksi kepada Iran.

H2: Negara A memaksa negara B mengakui superioritas kapabilitas negara A:

AS meminta Iran untuk menghentikan aktivitas nuklir.

\section{Skenario 2}

Iran yang tidak dapat menerima sikap AS mengancam akan menutup Selat Hormuz dan meminta AS untuk tidak melanjutkan tekanan terhadap Iran (Adharsyah, 2019). Dari skenario 2, juga dapat dilihat Iran menggunakan pendekatan Confrontation Strategy untuk merespon tindakan AS. Hal ini dapat dijelaskan sebagai berikut:

H1: Negara A mempertajam isu konflik terhadap negara B:

Iran merespon sanksi yang diberikan AS dengan mengancam akan menutup Selat Hormuz. Hal ini akan membuat distribusi minyak mentah tidak stabil.

H2: Negara A memaksa negara B mengakui superioritas kapabilitas negara A:

Iran meminta agar AS menghentikan tekanan agar mereka membatalkan ancamannya untuk menutup Selat Hormuz.

Kedua skenario di atas menjelaskan bahwa tindakan yang dilakukan Iran dan AS memang merupakan suatu tindakan yang konfrontatif. Hal ini jelas terlihat dari kebijakan luar negeri yang diambil oleh masing-masing negara, yang menunjukkan adanya aksi-reaksi saling memamerkan kapabilitas negaranya untuk menekan pihak lain. Dalam pandangan realis, hal ini dapat terjadi karena kedua negara melihat sistem internasional sebagai sesuatu yang anarki, sehingga keduanya memiliki pola pikir selfhelp (tidak mengandalkan pihak lain). Dengan cara pikir seperti ini, maka mereka akan terus berusaha melakukan apapun demi mencapai kepentingan nasionalnya. 
Kedua skenario di atas, juga merupakan skenario pembuka bagi rentetan konflik-konflik yang akan terjadi di Selat Hormuz. Iran telah meningkatkan aktivitas militernya di Selat Hormuz dan menggertak siapapun yang memberikan ancaman terhadap kedaulatannya. Sementara AS juga ikut menambah kekuatannya dengan mengirimkan sejumlah tentara dan kapal perangnya untuk mengawal kapal tanker yang membawa minyak untuk melewati Selat Hormuz. AS juga mengajak masyarakat internasional untuk ikut mengawasi jalur perdagangan minyak di Selat Hormuz. Belakangan diketahui beberapa negara, seperti Inggris dan Australia, juga mengikuti AS untuk melindungi kapal-kapal yang melintasi selat tersebut dalam upaya melawan ancaman militer Iran (Mueller, 2019; Tarabay, 2019).

Pasca mundurnya AS dari JCPOA yang diikuti oleh ancaman Iran untuk menutup Selat Hormuz, eskalasi konflik militer di kawasan tersebut menjadi meningkat. Eskalasieskalasi tersebut di antaranya adalah, pada Juli 2019, Iran menahan kapal Stena Impero berbendera Inggris dengan tuduhan melanggar hukum laut internasional di Selat Hormuz. Penahanan ini diduga balasan Iran bagi Inggris yang dua minggu sebelumnya juga menahan kapal Iran di Gibraltar (Aljazeera 2019b). Pada bulan Mei 2019, otoritas Uni Emirat Arab menyatakan bahwa dua tanker minyak Saudi menjadi korban serangan sabotase di lepas pantai Fujairah milik Emirat. UEA tidak menyebutkan siapa pihak yang bertanggung jawab atas serangan tersebut, namun kejadian ini menambah ketegangan di kawasan (Wirayani, 2019). Pada Juli 2019, Iran menembak jatuh drone AS yang memasuki wilayah Iran dan pada Juli 2019, AS membalas menembak jatuh drone Iran (CNN, 2019). Bahkan meskipun pandemi Covid19 sedang berlangsung, konfrontasi militer Iran dan AS di perairan itu tetap berlanjut. Hingga tanggal 12 Agustus 2020 The International Maritime Security Construct (IMSC) melaporkan bahwa Iran masih melakukan aktivitas militernya, yaitu dengan melakukan aktivitas boarding persenjataan di kapal komersial di perairan internasional (Defence Visual Information Distribution Service, 2020). Bila hal ini benar dilakukan Iran, ini merupakan pelanggaran terhadap hukum internasional yang merusak kebebasan bernavigasi dan arus perdagangan bebas.

Konflik di antara Iran dan AS terkait Selat Hormuz bukanlah hal baru. Pada saat Iran dipimpin oleh Presiden Ahmadinejad (2005-2013), pola yang sama juga terjadi, yaitu AS menunduh Iran telah mengembangkan senjata nuklir dan melakukan embargo ekonomi terhadap Iran (Stivachtis, 2018). Waktu itu Iran juga membalas dengan ancaman akan menutup Selat Hormuz jika sanksi yang diberikan AS. Pola terdahulu itu, masih sama dengan pola konfrontasi Iran dan AS pasca JCPOA sebagaimana telah dijelaskan di atas. Bagi kaum realis, alasan mengapa negara saling menunjukkan kapabilitasnya, terutama di bidang militer, adalah karena menurut mereka keamanan 
nasional adalah masalah utama, power adalah konsep utama dalam menjamin keamanan negara. Selain itu, kaum realis juga melihat bahwa isu militer adalah bagian dari isu politik yang dominan di dunia (Saeri, 2012: 10-12). Pemikiran realisme tentang negara dan teori Strategi Kebijakan Luar Negeri yang dijabarkan Lovell dalam melihat pola aksi-reaksi antar negara dapat menjelaskan mengapa konfrontasi Iran dan AS di Selat Hormuz akan terus berlanjut.

\section{Simpulan}

Konfrontasi Iran dan AS yang terjadi di Selat Hormuz merupakan konflik yang membuat dunia khawatir karena konflik tersebut membuat pasokan minyak global dunia terganggu. Sebagaimana diketahui publik, seperlima pasokan minyak dunia melintasi selat tersebut. Minyak merupakan kebutuhan vital bagi suatu negara sebab ia merupakan sumber penggerak perindustrian. Apalagi ketika memasuki abad ke-21, dengan tuntutan globalisasi setiap negara dipaksa untuk memacu pertumbuhan ekonominya, dunia industri pun semakin digalakkan. Maka tidak mengherankan jika konfrontasi Iran dan AS di Selat Hormuz membuat dunia khawatir, sebab hal ini dapat menghambat pertumbuhan ekonomi banyak negara di dunia.

Ancaman Iran untuk menutup Selat Hormuz bukanlah tanpa alasan. Hal ini mereka lakukan karena AS menarik diri dari kesepakatan JCPOA yang sebelumnya telah membuat hubungan kedua negara membaik. Melalui kesepakatan JCPOA, sanksisanksi yang diberikan Barat kepada Iran dihapuskan, dan karenanya perekonomian Iran dapat tumbuh. Tetapi setelah AS menarik diri dari kesepakatan ini, mereka mengembalikan sanksi-sanksi yang sebelumnya sudah dihapuskan. Iran yang merasa dirugikan akan sikap AS melakukan perlawanan dengan mengancam akan menutup Selat Hormuz.

Dengan menggunakan pendekatan Confrontation Strategy kedua negara itu saling menunjukkan kekuatan kapabilitas negaranya dan memaksa pihak lawan untuk mengakui superioritas kemampuan kapabilitas negara mereka. Dalam skenario 1 maupun skenario 2 yang telah dijelaskan dalam bagian pembahasan terlihat bahwa keduanya menjadi sebuah pola aksi-reaksi yang daur sebab masing-masing menggunakan strategi yang sama dalam merespon tindakan satu sama lain. Akibatnya, selama kedua pihak tetap dalam posisi saat ini, diprediksi konfrontasi di sekitar Selat Hormuz akan tetap berlangsung. 


\section{Daftar Pustaka}

ACIL Tasman. (2012). NESA Identified Issues: Strait of Hormuz. [online]. Dalam: https://www.energy.gov.au/sites/default/files/nesa-identified-issues-straithormuz-2012.pdf. [diakses 3 Oktober 2020].

Adharsyah, T. (2019). Iran Ancam AS, Harga Minyak Naik. CNBC, [online]. Dalam: https://www.cnbcindonesia.com/market/20190822093421-17-93802/iran-ancamas-harga-minyak-naik [diakses 3 Oktober 2020].

Bacon, J. (2018). Iran nuclear deal: Hassan Rouhani says deal could survive without U.S. USA Today, [online]. Dalam: https://www.usatoday.com/story/news/world/2018/05/07/iran-nuclear-dealhassan-without-u-s/585867002/ [diakses 3 Oktober 2020].

Council on Foreign Relations. (2018). The Return of U.S. Sanctions on Iran: What to Know. [online]. Dalam: https://www.cfr.org/in-brief/return-us-sanctions-iranwhat-know [diakses 3 Oktober 2020].

Council on Foreign Relations. (2020). Confrontation Between the United States and Iran. [online] Dalam: https://www.cfr.org/global-conflicttracker/conflict/confrontation-between-united-states-and-iran [diakses 3 Oktober 2020].

CNBC. (2019). AS-Iran di Ambang Perang Gara-gara Drone, Ini Ceritanya. [online]. Dalam: https://www.cnbcindonesia.com/news/20190621165512-4-79917/as-irandi-ambang-perang-gara-gara-drone-ini-ceritanya [diakses 3 Oktober 2020].

CNN. (2019). Trump Balas Tembak Jatuh Drone Iran. [online]. Dalam: https://www.cnnindonesia.com/internasional/20190719083457-

134413522/trump-balas-tembak-jatuh-drone-iran [diakses 3 Oktober 2020].

Dehghan, S. K. (2018) Iran threatens to block Strait of Hormuz over US oil sanctions Iran. The Guardian, [online]. Dalam: https://www.theguardian.com/world/2018/jul/05/iran-retaliate-us-oil-threats-euvisit-hassan-rouhani-trump [diakses 3 Oktober 2020].

Defence Visual Information Distribution Service. (2020). IMSC Statement on the Incident with Motor Tanker. [online]. Dalam: https://www.dvidshub.net/news/375890/imsc-statement-incident-with-motortanker-wila [diakses 3 Oktober 2020].

DW. (2020). Europe, China and Russia urge preservation of Iran nuclear deal. [online]. Dalam: https://www.dw.com/en/europe-china-and-russia-urge-preservation-ofiran-nuclear-deal/a-52544410 [diakses 3 Oktober 2020]. 
Faradiba, B. (2016) Sikap Amerika Serikat Terhadap Kegiatan Militer Iran Di Selat Hormuz Di Masa Ahmadinejad (2011-2013). Sripsi Universitas Islam Negeri Syarif Hidayatullah Jakarta. [online] Dalam: http://repository.uinjkt.ac.id/dspace/bitstream/123456789/40910/2/BALQIS FARADIBA-FISIP.pdf.

Global Fire Power. (2020a). Iran Military Strength. [online]. Dalam: https://www.globalfirepower.com/country-military-strengthdetail.asp?country_id=iran [diakses 3 Oktober 2020].

Global Fire Power. (2020b). Military Strength Ranking. [online]. Dalam: https://www.globalfirepower.com/countries-listing.asp [diakses 3 Oktober 2020].

Al Jazeera. (2019a). Understanding the Iran deal: What, why and the next steps. [online]. $\quad$ Dalam: https://www.aljazeera.com/economy/2019/05/08/understanding-the-iran-dealwhat-why-and-the-next-steps/ [diakses 3 Oktober 2020]

Al Jazeera. (2019b). Seized UK-flagged tanker Stena Impero leaves Iranian port. [online]. Dalam: https://www.aljazeera.com/news/2019/9/27/seized-uk-flaggedtanker-stena-impero-leaves-iranian-port. [diakses 3 Oktober 2020]

Kahn, M. (2016) Growth star India overtakes China as world's fastest growing major economy. Telegraph, [online]. Dalam: https://www.telegraph.co.uk/finance/economics/12146579/India-overtakesChina-as-worlds-fastest-growing-major-economy.html [diakses 3 Oktober 2020].

Katzman, K. et al. (2012). Iran's threat to the strait of hormuz, Bypassing Iran: Petroleum Production and the Strait of Hormuz. FAS, [online]. Dalam: https://fas.org/sgp/crs/mideast/R42335.pdf. [diakses 3 Oktober 2020]

Lovell, J.P. (1970). Foreign Policy in Perspective: Strategy, Adaptation, Decision Making. New York: Holt, Rinehart and Winston, Inc.

Mas'oed, M. (1998). Teori dan Metodologi Hubungan Internasional. Yogyakarta: Pauss Universitas Gajahmada.

Mikail, K. (2018). Perjanjian Nuklir Iran dan Kepentingan AS-Israel di Timur Tengah. Jurnal ICMES, [online] 2(1), 69-85. Dalam: https://doi.org/10.35748/jurnalicmes.v2i1.18 . [diakses 27 November 2020].

Mueller, B. (2019). U.K. joins U.S.-led Effort to Protect Ships in Straits of Hormuz. New York Times, [online]. Dalam: https://www.nytimes.com/2019/08/05/world/middleeast/britain-iran-strait-ofhormuz.html. [diakses 27 November 2020]. 
Nuriansyah, F. (2014). Strategi Kebijakan Pertahanan Iran Di Selathormuz Dalam Menghadapi Amerika Serikat Periode 2011-2012. Skripsi UPN "Veteran" Jakarta. Dalam: http://repository.upnvj.ac.id/5664/2/AWAL.pdf . [diakses 27 November 2020].

Perwita, A. A. B. dan Razak, M. I. (2020). U.S. Foreign Policy Towards Iranian Nuclear Threat from Bill Clinton to Donald Trump Administration. Insignia Journal of International Relations. [online] 7(1), 17-44. Dalam: https://doi.org/10.20884/1.ins.2020.7.1.2224. [diakses 27 November 2020]

Pham, J. P. (2010). Iran's threat to the strait of hormuz: A realist assessment. American Foreign Policy Interests, [online] 32(2), 64-74. Dalam https://doi: 10.1080/10803921003697542. [diakses 27 November 2020]

Pujayanti, A. (2019.) Sengketa Nuklir Iran-Amerika Serikat, Kajian Singkat Terhadap Isu Aktual dan Strategis. Jakarta. DPR, [online]. Dalam: https://berkas.dpr.go.id/puslit/files/info_singkat/Info\%20Singkat-XI-10-II-P3DIMei-2019-179.pdf. [diakses 27 November 2020]

Rahim, M. H. (2019). Post-JCPOA: Diplomasi Koersif Amerika Serikat Vis-À-Vis Iran. Jurnal ICMES, [online] 3(1), 27-52. Dalam: https://doi.org/10.35748/jurnalicmes.v3i1.42 . [diakses 3 Oktober 2020].

Carrel-Billiar, F. and Wing, C. (2010). Iran and the NPT. International Peace Institute, [online]. Dalam: https://www.ipinst.org/wpcontent/uploads/2010/04/pdfs_iranchapt.pdf. [diakses 3 Oktober 2020].

Ratner, M. (2018.) Iran's Threats, the Strait of Hormuz, and Oil Markets: In Brief. FAS, [online]. Dalam: https://fas.org/sgp/crs/mideast/R42335.pdf. [diakses 3 Oktober 2020].

Saeri, M. (2012). Teori Hubungan Internasional Sebuah Pendekatan Paradigmatik. Jurnal Transnasional, [online] 3(2), 1-19. Dalam: https://transnasional.ejournal.unri.ac.id/index.php/JTS/article/viewFile/70/64. [diakses 3 Oktober 2020].

Salsabila, F.R., \& Yulianti, D. (2019). Security Dilemma dalam Ketegangan AS-Iran Pasca Serangan Kapal Tanker di Teluk Oman. Jurnal ICMES, [online] 3(2), 200-222. https://doi.org/10.35748/jurnalicmes.v3i2.56.

Saputra, F. (2013). Latar Belakang Pemerintah Iran Atas Wacana Penutupan Selat Hormuz Tahun 2011. Skripsi, UPN "Veteran" Yogyakarta. Dalam: http://repository.upnyk.ac.id/6030/ [diakses 3 Oktober 2020].

Stivachtis, Y. A. (2018). United States Foreign Policy in the Middle East after the Cold War. Dalam: Y.A. Stivachtis, ed., Conflict and Diplomacy in the Middle East Conflict 
and Diplomacy in the Middle East. E-International Relation, [online]. Dalam: https://www.e-ir.info/publication/conflict-and-diplomacy-in-the-middle-eastexternal-actors-and-regional-rivalries/. [diakses 3 Oktober 2020].

Talmadge, C. (2008). Closing Time: Assessing the Iranian Threat to the Strait of Hormuz. International Security, [online] 33(1), 82-117. Dalam: https://www.belfercenter.org/sites/default/files/legacy/files/IS3301_pp082117_Talmadge.pdf. [diakses 27 November 2020]

Tarabay, J. (2019). Australia is Third Country to join U.S. in Patroling Strait of Hormuz. New York Times, [online] Dalam: https://www.nytimes.com/2019/08/21/world/australia/ships-hormuz.html. [diakses 27 November 2020]

U.S. Energy Information Administration. (2019). The Strait of Hormuz is the world's most important oil transit chokepoint. [online] EIA. Dalam: https://www.eia.gov/todayinenergy/detail.php?id=39932 [diakses 3 Oktober 2020).

VOA Indonesia. (2019). PM Israel Klaim Temukan Situs Baru Nuklir Iran. [online]. Dalam: https://www.voaindonesia.com/a/pm-israel-klaim-temukan-situs-barunuklir-iran/5077055.html [diakses 3 Oktober 2020].

U S Energy Information Administration. (2007). https://doi.org/10.5860/choice.44-3624.

Wirayani, P. (2019). Hubungan AS-Iran Panas, Kapal Tanker Arab Saudi Diserang. CNBC, [online]. Dalam: https://www.cnbcindonesia.com/news/20190513122328-472052/hubungan-as-iran-panas-kapal-tanker-arab-saudi-diserang [diakses 3 Oktober 2020].

Yani, Y. M. (2008). Perspektif-Perspektif Politik Luar Negeri: Teori dan Praksis. Pustaka Unpad, [online]. Dalam: http://pustaka.unpad.ac.id/wpcontent/uploads/2010/06/perspektif_perspektif_politik_luar_negeri.pdf. [diakses 3 Oktober 2020]. 